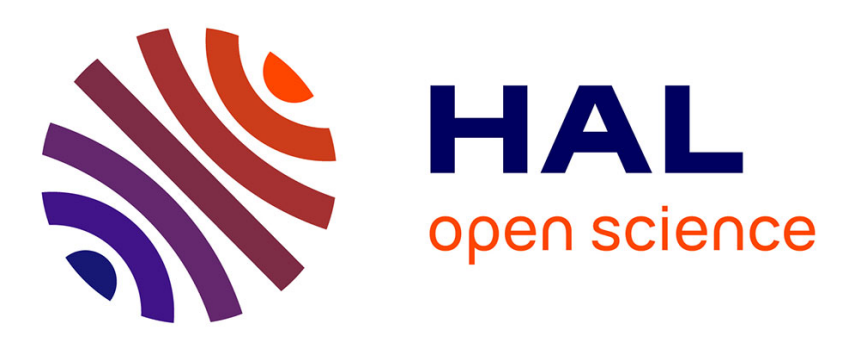

\title{
Time perspective and cannabis use: Why and how it is more complex than we think
}

\author{
Nicolas Fieulaine
}

\section{To cite this version:}

Nicolas Fieulaine. Time perspective and cannabis use: Why and how it is more complex than we think. Aleksandra Kostić; Derek Chadee. Time Perspective. Theory and Practice, Palgrave Macmillan, pp.195-215, 2017, 978-1-137-60191-9. 10.1057/978-1-137-60191-9_9 . hal-02419813

\section{HAL Id: hal-02419813 \\ https://hal.science/hal-02419813}

Submitted on 19 Dec 2019

HAL is a multi-disciplinary open access archive for the deposit and dissemination of scientific research documents, whether they are published or not. The documents may come from teaching and research institutions in France or abroad, or from public or private research centers.
L'archive ouverte pluridisciplinaire HAL, est destinée au dépôt et à la diffusion de documents scientifiques de niveau recherche, publiés ou non, émanant des établissements d'enseignement et de recherche français ou étrangers, des laboratoires publics ou privés. 


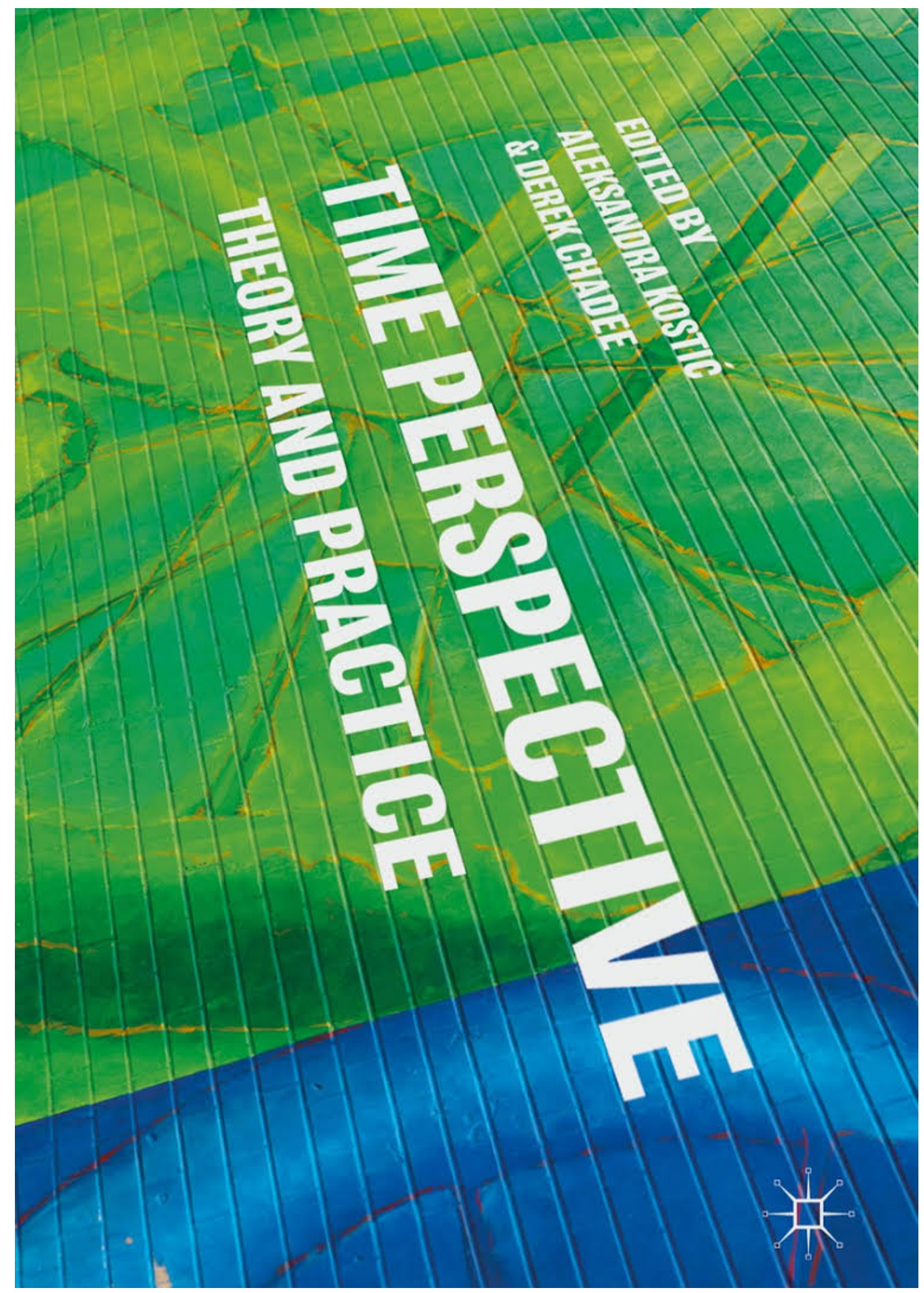


Title

Time perspective and cannabis use: Why and how it is more complex than we think

Author

Nicolas Fieulaine

Associate Professor

Social psychology Research Group

University of Lyon

Nicolas.fieulaine@univ-lyon2.fr

Abstract

Time perspective was repeatedly evidenced as closely related to risky behaviors, and particularly substance use. From this research, future orientation appeared as a protective factor against substance use, whereas present time orientation was established as a risk factor. In this chapter, we review evidence of such a relation, but also highlight contradictory findings. When taking into account constructs related to self-regulation or risk perception, one may note that TP relation to health behaviors and substance use is more complex than expected. On the basis of recent studies, we then explore this complex relation and we propose some theoretical perspectives and a research agenda for a better understanding of and for more efficient interventions on- substance and cannabis use behaviors.

Keywords: Time perspective - substance use - addictive behaviors - risk perception - selfregulation

\section{WORDCOUNT:}

7227 words (references included)

20 pages - 91 references 


\section{Time perspective in substance use}

Growing research in the last decade evidenced that time perspective (TP) is a strong psychosocial predictor of many behaviors, particularly in the field of health (Boyd \& Zimbardo, 2005; Henson, Carey, Carey \& Maisto, 2005; Crockett \& al. 2009; Guthrie \& al., 2009). From the perspective of Zimbardo \& Boyd (1999), which postulate that TP consists of five factors based on orientation and attitudes towards timeframes, several studies have shown that present orientation, in a hedonistic and sensation-seeking attitude (Present-hedonistic time perspective - PHTP), and future orientation, in a planning and goal-oriented attitude (Future time perspective - FTP), are the most predictive factors in health behaviors, and in substance use (Keough \& al., 1999; Wills \& al., 2001; Apostolidis, Fieulaine, Simonin \& Rolland, 2006). While individuals focused on future time perspective (FTP) are more likely to engage in health protective behaviors and to avoid risky ones, individuals predominantly possessing a present hedonistic time perspective (PHTP) are more likely to adopt risky behaviors (e.g. Henson, Carey, Carey \& Maisto, 2005, Crockett, Weinman, Hankins \& Marteau, 2009).

Early work by Smart (1968) showed that alcoholics had a less extensive and coherent FTP future than social consumers. Patients included in an addiction management program are less motivated by the future than a student population (Lavelle, Hammersley, \& Forsyth, 1991). Alvos, Gregson, \& Ross (1993) found that current injecting drug users had a truncated FTP, a perspective of loss and isolation compared to previous drug users. In several studies, direct links have been established between TP, as measured by ZTPI, and substance use. Thus, a future orientation appeared to be protective of substance use, whether heroin, cannabis, alcohol or tobacco (Daugherty \& Brase, 2010; Petry, Bickel, \& Arnett, 1998; Henson, Carey, Carey, \& Maisto, 2006, Keough et al., 1999, Wills, Sandy, \& Yaeger, 2001, Klingemann, 2001, MacKillop, Mattson, MacKillop, Castelda, \& Donovick, 2007, Fieulaine \& Martinez, , Fineulaine, Martinez, \& Al., 2011, Adams \& Nettle, 2009, Apostolidis, Fieulaine \& Soule, 2006, Guthrie, Butler \& Ward, 2009, Hall, Fong, Yong \& al, 2012; Barnett \& al., 2013). These findings on the protective role of FTP apply either to lowering consumption or for more frequent (and successful) stopping attempts, whereas the present orientation was related to a more frequent and intense substance use (Daugherty \& Brase, 2010, Petry \& Al., 1998, 
Henson, Carey \& Al., 2006, Keough, Zimbardo \& Boyd 1999, Wills \& Al., 2001, Klingemann 2001, MacKillop \& Al., 2007, Fieulaine and Martinez, 2010, 2011, Adams \& Nettle, 2009, Apostolidis, Fieulaine \& A1., 2006, Guthrie \& A1. Hall, Fong, Yong \& A1., 2012, Milfont, Andrade, Pessoa, \& Belo, 2008; Chavarria \& al., 2015).

The hypothesis underlying the consideration for the temporal dimension in this field of research is that health behaviors fundamentally involve temporal dilemmas (Hall \& Fong, 2007), creating conflicts between immediate benefits and future costs (in the case of risktaking behaviors), or between immediate costs and future benefits (in the case of health protective ones). Time preference and time orientation thus appeared as personality variables likely to influence, more or less directly, the decision-making process. While time preference corresponds specifically to the differential value attached to outcomes in relation to temporal location for a particular behavior or event (Fuchs, 1982; Chapman \& Coups, 1999; Chapman, Brewer, Coups, Brownlee, Leventhal \& Leventhal, 2001; Chapman, 2001), temporal orientation corresponds to the attention paid to the past, present, and future time frames across a broader range of situations (Cottle, 1968 ; Zaleski, 1994; Finke, 2005). Both have been extensively acknowledged in relation to preventive and risky health behaviors, and from these studies it emerges that future time preference and orientation, (as opposed to present preference and orientation), is associated with less risky and with more preventive behaviors, and this for a variety of health behaviors (e.g. Agnew \& Loving, 1998; Björgvinsson \& Wilde, 1996; Strathman, Gleicher, Boninger \& Edwards, 1994; Chapman \& Coups, 1999; Orbell \& Kyriakaki, 2008).

\section{Temporal dilemmas}

These findings are interpreted in relation to a variety of models and theories, but usually they are seen as the result of a reduction of future time horizons leading to increased preference for immediate positive effects at the expense of potential and long-term risks in the future (Petry \& Al., 1998). This temporal myopia or "presentism" is responsible of a reduced sensibility to long term risks, and increase the discounting of delayed consequences of substance use. Then, immediate gratifications such as alleviating pain related to dependency, or spending a good moment with friends are valued in comparison with long term benefits of abstinence, reduced consumption or cessation (good health, longer living, dependence reduction, financial 
savings...). The aversive effects (diseases, dependency, social and legal risks...), meanwhile, are devalued because generally delayed in time. Hence, the shortening of time horizons minimizes their subjective probability, whereas the immediate benefits are made more present in mind. On the other side, regarding substance use cessation, reduction or abstinence, the costs are immediate (resisting temptations, being excluded by a group, lasting pain or depressive mood...) while the benefits are delayed. Then the temporal dilemma individuals face when confronted to substance use is as follow:

\begin{tabular}{|l|l|l|}
\hline & Present & Future \\
\hline Benefits & Use & Abstinence or cessation \\
\hline Costs & Abstinence or cessation & Use \\
\hline
\end{tabular}

Temporal dilemma in relation to substance use (note: these trade-off can differ from one substance to another)

These temporal dilemmas are also deeply influenced by the neural, social and emotional consequences of substance use (Lende \& Smith, 2002). Depending on which substance is consumed (Barnett \& al., 2013), at which level and in which conditions, these addictive behaviors may have an impact on individuals' relation to time. Hence, emphasis on the present and loss of interest for the future was repeatedly observed in drug users. Also, group norms in substance abusers have to be in line with the necessity to maintain group practices an identity, and therefore to normalize a risk denial based for a part on presentism and temporal myopia. The neural consequences of substance use and of addiction also reinforce the capacity to delay gratification, to self-control in relation to future outcomes and to regulate impulsivity and craving. In relation to illegal drug use, the legal risks and punitive policies for drug users increase instability and insecurity in everyday life, and therefore the capacity to envision the future with confidence. This lack of future perspective is at odds for prevention and treatment of addictions, as it will be illustrated.

Beyond the economic models of addiction, where time perspective is conceived as a factor in rational trade-offs between temporally located costs and benefits, the impact of time perspective in health behaviors was related to a variety of behavioral theories. Hence, the temporal basis of individuals' decisions and behaviors was related to the theory of selfregulation (Hall \& Fong, 2007), to self-determination theory (Wininger \& De Sena, 2012), the theory of planned behavior (Richard \& al ; 1996) or in the early description of the social 
cognitive theory by Bandura (Bandura, 1991). In a recent provocative editorial, Sniehotta and colleague, while suggesting to « retire » the theory of planned behavior, identified promising avenues of theory development to explain health behaviors, included « theories with emphasis on temporal dynamics (...) and temporal frames adopted by individuals » (Sniehotta \& al., 2014, p. 5) .

\section{A more complex relation: the case of cannabis use}

Nevertheless, results are sometimes inconsistent with this general statement (Guthrie \& al. 2009; Adams \& Nettle, 2009), and several studies made appear no links between time perspective and substance use. One reason for this inconsistency may be the intervention of other variables, which can buffer, reinforce or reverse this relation. In recent research, TP was related to other self-regulatory constructs and to risk perceptions to explain how and why individuals' relation to time may intervene in substance use behaviors.

Cannabis use is a good illustration of such a complexity. Cannabis is the most widely used substance labeled as a "drug", and its usage is largely normalized in youths and in adults despite its illegal status in many countries. Its usage questions the balance between health, social and legal risks, and the benefits associated with social inclusion, group identity and also the palliative role when facing depressive or anxious states. Users are facing the major risk of being labeled as deviant, or to accept this social status and to build a culture around it. Despite these specificities, cannabis use was repeatedly related to time preference, orientation or perspective. Beyond the simplistic hypothesis defining future orientation as a protective factor and present orientation as at risk, several studies were designed to explore further the underlying processes involved.

\section{The role of self-regulation}

Among the potential intervening variables, self-control appears to be of particular importance, given its central role in self-regulation processes. Hence, in self-regulation theories, a key predictor of self-regulation capacities is the way individuals differ in their basic styles of selfcontrol (Baumeister, Vohs \& Tice, 2007). Self-control relate to the process through which people manage their dispositional tendencies and control their thoughts, feelings, impulses and task performance in order to be consistent with their goals and standards of behaviors, 
and is a basic element of the capacity to self-regulate (cf. Baumeister, Gailliot, DeWall \& Oaten, 2006; Rasmussen, Wrosch, Scheier \& Carver, 2006). As various studies evidenced, people with high abilities to self-control are less vulnerable to impulsivity and delay more gratification than people with low self-control (DeRidder \& DeWitt, 2006), opening a way for alternative interpretation of the impact of temporal factor. Therefore, people with low capacities to regulate appeared as more susceptible to engage in substance use, to sustain their consumption et to have difficulties in quitting (Wills, Sandy \& Yaeger, 2002 ; Wills \& Stoolmiller, 2002 ; Wills, Ainette, Stoolmiller, Gibbons \& Shinar, 2008). Beyond its main effect on substance use (Brody \& Ge, 2001; Wills, Walker, Mendoza \& Ainette, 2006), selfcontrol repeatedly appeared as a buffering agent in the relation of risk factors to substance use behaviors (Wills \& al., 2008; Wills, Pokhrel, Morehouse \& Fenster, 2011). In these studies, having good (or high) self-control appears to be negatively related to substance use, and to reduce the impact of risk factors on substance use. This buffering effect of self-control on the impact of risk factors to substance use has been extensively acknowledged for different populations, using a variety of methods (see Wills \& al., 2008 for a review).

In relation to time, self-control, and self-regulatory capacity in general, are deeply temporally based (Hall \& Fong, 2007) and shaped (Wills, Sandy \& Yaeger, 2001; Joireman, Balliet, Sprott, Spangenberg \& Schultz, 2008). Balancing short term and long term consequences of decisions and behaviors can adequately be considered as the core definition of self-control, and several studies suggested that TP and self-control are not only intercorrelated, but also interact in their impact on behaviors (Joireman \& al., 2008; Barber \& al., 2009).

Hence, some studies related to self-regulation theory have found evidence of the buffering effect of self-control on substance use with regard to risk factors (Wills, Walker, Mendoza \& Ainette, 2006). In these studies, having good (or high) self- control appears to be negatively related to substance use, and to reduce the impact of risk factors on substance use (e.g. Wills, Ainette, Stoolmiller, Gibbons \& Shinar, 2008). In two independent studies, we demonstrated that the relation of time perspective with cannabis use could be reversed when taking into account a self-regulatory construct, namely the construct of desire for control (DC, Burger \& Cooper, 1979). It corresponds to the desire or motivation to maintain control, make one's own decisions, and be in charge of one's activities. DC is presumed to be a source of motivation for control, varying from situation to situation but resulting in a general and measurable level, and is depicted as an important dispositional factor within various phenomena, such as 
achievement, psychological adaptation, stress, or health (Burger, 1992; Gebhardt \& Brosschot, 2002). DC is distinct from other measures related to perceptions or beliefs about control, given that it examines the degree to which control is attractive, desirable and valuable, while other measures generally assess the level to which, and how, control is attained (cf. Skinner, 1996).

The first study (Fieulaine \& Martinez, 2010), conducted in a sample of 240 people from general population in France and using measures of TP (Present-hedonistic/PHTP and future/FTP subscales of the ZTPI), desire of control (Burger \& Cooper, 1979) and cannabis use, demonstrated that the more people are focused on PHTP, the more they report substance use, and the more they are focused on FTP, the less they consume. No relation appeared between DC and substance use. But when testing for a potential buffering effect of desired control in the relation of TP to cannabis use, it appeared that the positive relations between PHTP and substance use and the negative one between FTP and substance use are lowered and even disappeared in some cases when individuals scored low on dimensions of desire for control. Thus, if TP is a risk (for $\mathrm{PH}$ ) and a protective (for $\mathrm{F}$ ) factor in substance use, it is dependent on another psychological construct related to self-regulation. Both in relation to personal experiences, values and living conditions, TP and DC interact in establishing what one can considered as social-psychological vulnerability profiles for substance use (Fieulaine \& Martinez, 2010,p. 6).

This first study (Fieulaine \& Martinez, 2011) was completed by a second one, designed as prospective, with measures of DC, TP and planned behavior components in addition assessed at Time 1, and cannabis perceptions and behavior assessed one week later (Time 2).

Participants were 690 high school students, recruited in all classes of two high schools located in an metropolitan area in center France, 664 at follow-up, a response rate of 96,3\%. We used the full ZTPI scale, in order to uncover potential effect of other time perspective dimensions beyond the $\mathrm{PH}$ and $\mathrm{F}$ ones.

Results revealed that several TP subscales were significantly related to predictors of cannabis use intention. Hence, PHTP appeared as positively related to attitudes towards cannabis use, to perceived norms and control favoring cannabis use, whereas FTP is negatively related to these constructs. Results also revealed a significant negative relation of PPTP to predictors of cannabis use intention (attitude and control, diminishing intentions). They also revealed that if PHTP is positively related to cannabis use intention or behavior, it is trough its impact on 
attitudes, subjective norms and perceived control related to this behavior. FTP, on the other hand, remains a direct significant predictor of intention after having entered the TPB variables. Therefore, FTP has a direct impact on intention, which in turn mediate its relation to behavior.

These results confirmed, using a prospective study design, the predictive role played by time perspective in cannabis use, as a distal dispositional construct leading to greater positive views on cannabis use, and to higher subsequent intentions and behaviors. But in further analyses, it appeared that the TP X DC interaction was a direct predictor of intention, indicating a buffering role of control in the relation of TP to cannabis use intentions. Hence, in line with previous findings, the positive relation of PH and the negative one of FTP to intention was enhanced when individuals scored higher on the DC dimension.

In these studies, the well-established predictive role of future and present-hedonistic TP in substance use appears to be conditioned by the level of desire for control. High desire for control thus support the protective role of future orientation, but simultaneously reinforce the risk factor present hedonistic orientation represents.

As a consequence, self-control, as broadly defined, may bring to confusion between time and control, and lead to counterproductive interventions, and there is a strong need to further our understanding of the role psychological time and control play in self-regulation processes and particularly in substance use. These results lead to question the role desire for control may play in the impact of TP as a dispositional risk factor for substance use. To focus on sensation seeking and pleasure in the present, with low concern for future consequences is related to highest substance use only for those who simultaneously are motivated for controlling their life and situation. In the same way, being focused on future issues in a planning and conscientious attitude is linked to lower substance use only when simultaneously related to a high desire to control one's life. More important in a self-regulation perspective, motivation to control has no main effect on substance use but acts only as a buffering agent, enhancing or reducing the impact of TP on substance use. Hence, if DC has to be considered as a fuel in self-regulation processes, this is through its activating or inhibiting role on the impact of a dispositional factor such as time perspective. Therefore, these distal predictors of behavioral edification seem to find their energetic role as a mixture of fuels for the proximal muscular activity of self-regulation. 


\section{The role of risk perceptions}

Other constructs of interest, susceptible to contribute to our understanding of how and why TP impacts substance use are risks perceptions, particularly in the case of cannabis. Indeed, the double face of cannabis - normalized and illicit or dangerous - establishes a specific relationship to the substance, to conciliate the private dimension of the practice with its institutional definition as illegal and deviant (Hammersley \& al., art. cit.). Hence a main goal in substance perceptions is to get away from the "risky" label, which generally defines behavior and individuals as "deviant" and/or "drug-takers". Because of the risk of stigmatization, neutralization strategies are established, which in fact create a distinction between cannabis and other drugs perceived as "hard" (Peretti-Wattel, 2003), and therefore a denial of risks, particularly in consumers. Thus, risk perceptions appear essential when analyzing the development of consumer behaviors; their increase, quitting or relapses (BoneyMcCoy, Gibbons, Reis, Gerrard, Luus \& Von Wald Suka, 1992). Beyond the denial of risks, risk perceptions are considered as one of the key factors to explain risky behaviors (Brewer \& al., 2004) such as substance use (Virgili \& al., 1991). Previous and recent increases or decreases in cannabis use were explained first by the changes in people's views of the substance and of perceived risks (Bachman \& al., 1998 ; Terry-McElrath \& al., 2017). Hence, higher perceived risks were associated with lower levels of consumption, whereas lesser perceived risks were associated with higher levels of use (occurrence, frequency, quantity; e.g. Kilmer, 2007). Economic models relates behaviors to the individuals trade-off between costs and benefits, and the more recent take into account the temporal discounting of delayed rewards of risks (Svenson \& al., 1989). Personality models relate TP with risk propensity (Jochemczyk \& al., 2016) or similar constructs (e.g. sensation seeking; Lennings, 1991), whereas cognitive approaches relate TP to the sensitivity and awareness to future consequences (Strathman \& al., 1994). For substance use, TP could act as a potential predictor of risk perceptions, to be considered in explaining models. Surprisingly, only a very few studies explored systematically the relation of TP and risk perceptions (e.g. Griva \& al., 2013), despite the fact that previous findings illustrated the intervention of similar broad constructs in the link between behaviors and risk perceptions associated to the substance (e.g. sensation seeking, Rosenbloom, 2003), and that the relation of personality variables to health behaviors appeared to be mediated by proximal cognitive factors (Wills \& al., 2001). 
We performed two independent studies to explore how TP influence cannabis risks perceptions, cannabis use and their relation. In a first study conducted in a sample of 280 adolescents, we assessed Future TP, cannabis perceptions and cannabis use, and we observed the well established negative relation of FTP with cannabis use (usage and level), but also a significant relation of TP to cannabis perceptions. In subsequent meditational analyses, we established the meditational role of cannabis perception in the link between TP and cannabis use. Hence, if future-oriented adolescents were less prone to use cannabis and to use it frequently, it was for a large part because they perceived the cannabis as a drug and as a risky substance (Apostolidis \& al., 2006).

In a second study performed in a sample of 198 students, and using the full ZTPI, we observed that higher scores on FTP decreased the odds of consuming cannabis while higher scores on PHTP increased them, but also that the more the subjects were oriented towards FTP, the less they deny the risks associated with cannabis use, and the more they emphasize a "risk acceptance", which is the opposite for PHTP. Hence, TP is related to risks perceptions, in a directions that make FTP a protective factor. In congruence with the literature, we observed a decrease in the acceptance of risk and an increase in its denial among the most frequent consumers.

More surprisingly, moderating analyses showed that the positive relationship between consumption level and deny of risk was weaker for present-oriented subjects were and stronger when individuals were more future oriented. As consumption increases, focusing on the future leads to a larger denial of risks whereas an emphasis on the Present (fatalistic or hedonistic) improves the acceptance of risks. Thus, if FTP constitutes, and is generally considered as, a brake in the initiation of consumption, it may in fact facilitate a more regular consumption by supporting cognitive adjustments represented by the denial of risks. Actually, far from establishing a consumption barrier, FTP can support adhesion to a vision of the substance, that is to say, more denial and less assimilation to "hard" drugs, resulting in acceptability and maintenance of consumption.

Together, these findings suggest how complex is the relation of TP to substance use, and its intervention in determining addictive behaviors. In a very simplistic approach, FTP can be qualified as a protective factor, and Present TP as a risk factor for substance use. But when having a closer look and with a further exploration, one can note that these relations are far more nuanced and related to a variety of other constructs. Hence, FTP can become much less 
protective when related to a low desire for control, or when it reinforces a denial of risks in cannabis users. Or PHTP can lower vulnerability to substance use and abuse, when associated to a low desire for control or when it allows cannabis users to accept risks associated with consumption. There might be counterproductive effects in nudging future orientation in any case, without a closer look at the other variables involved, or without more integrative models of the process through which TP impacts substance use and health behaviors in general. Among others, putting emphasize in the desirability of future orientation may lead to wrong choices in intervention designs, and a lack of attention and acceptance to the various temporal orientations of targeted publics.

\section{How temporal frame matter}

In 1998, Orbell and colleagues conducted a series of studies to explore how individual differences in time orientation (using the concept of consideration of future consequences, Strathman et al. 1994) intervene in the receptivity and the sensibility to health promotion messages (Orbell and Hagger 2006; Orbell and Kyriakaki 2008; Orbell et al. 2004; Kees 2011). They varied the temporal framing of costs and benefits associated with promoted behaviors, so in one time frame negative consequences are presented as short term and the positive consequences as long term, and conversely in a second time frame (short term positive consequences and long term negative consequences). Findings revealed that futureoriented individuals were more sensitive to health communications and have greater intentions to engage in healthy behavior when the long-term consequences are positive and the short-term consequences are negative. In contrast, present-oriented individuals had greater intentions to perform promoted behavior when positive outcomes were presented as immediate and negative outcomes as delayed in the future.

These findings seem to be logical and almost intuitive. Since decades, psychology and marketing demonstrated that a tailored persuasive communication is more effective than a one-hat-fits-all strategy. But if applied to existing massive health promotion campaigns, this suggest that they could be ineffective for a large part of the public, in an arbitrary manner depending on which time frame is privileged by the designers of the campaign. Hence, some of the differences observed in cannabis use in relation to individuals' orientations may be for a part related to the differential impact of health campaigns. This is what we tested using an 
existing campaign promoting information seeking for excessive cannabis use. We presented the campaign to groups of students $\left(\mathrm{N}_{\text {toul }}=155\right)$ as it was designed by default, emphasizing mainly long-term benefits of being aware about the long-term risks of cannabis use. In a first step, participants were invited to fill in the CFC scale (Strathman et al. 1994) to assess their individual time orientation. After having we introduced the session participants were invited to listen cautiously the health promotion message presented by a research assistant introduced as a health educator. Finally, participants gave their evaluation through measures of message reception (attitudes, willingness to perform the promoted, recall of risks evoked). As in previous research, we found higher receptivity for the message in future oriented subjects than in present oriented ones. This result is quite disturbing, since the subjects who are the most at risk to be concerned by excessive substance use are the less sensitive to health communication intended to prevent excessive use.

And it may be the case for a large amount of health promotion or prevention campaigns, if no one among their designers nudge the campaign to be more adjusted to high priority target groupe. Temporal framing is in this context a particularly important dimension, just as the necessity to assess the time perspective of targeted populations. Fortunately, survey tools exist, in long and short forms, validated in many countries and by many studies; we just need the will to add this dimension in large survey to inform campaigns design.

\section{Conclusions: New look, new research, new practices}

Taken together, these research findings suggest the need for a more nuanced view on how the way we project ourselves in time may influence our behaviors, particularly in the context of risky behaviors like substance use. To keep an eye on the future may be optimal, but under certain circumstances only, and may be counterproductive in some case. Being focused on the present can be at risk in a variety of case, but also protective in some specific conditions. We, as researchers, must be cautious in the way we present research results, and to how the necessary simplification may lead to unfortunate consequences. Two research avenues seem to us opened following this review. First, we have to further our understanding of how TP relates to self-regulation theories. The interaction between control and time deserve in this objective a particular attention, to establish which configuration is more desirable under certain circumstances. For instance, how not only desire for control, but also self-control, 
perceived control and other control constructs are related to time perspective and therefore explain self-regulation processes, capacities or relapses ? How time is a condition to make a behavior intentional or unintentional, to activate one or another of the dual processes (automatic or controlled)? Second, there is a need to fill the gap between TP and risk perception fields of research. Delay discounting and inter-temporal choices offer a good basis to explore and test how individuals' time orientation can determine their choices when facing temporal dilemmas. Temporal framing is thereupon a relatively deserted topic, since the foundational studies by Orbell, but is for sure a critical question to address the issues of social inequalities in health, and how under-informed campaigns design can at least maintain social disparities, and at worst create social inequalities in health. A simple way to ensure for a complete examination of possible alternative message in relation to their temporal frames is to use a temporal framing canvas, as presented below.

\begin{tabular}{|c|c|c|}
\hline & & \multirow[b]{2}{*}{ Short term } \\
\hline & Long term & \\
\hline \multicolumn{3}{|l|}{ Costs } \\
\hline Benefits & & \\
\hline
\end{tabular}

Filling all the boxes might be a good nudge to avoid relying on his/her own temporal bias to design communications, and therefore to create implicit disparities in messages acceptability. Moreover, associated with a standard procedure to collect information on the temporal orientation of the target population (using Time Perspective measures, similar samples data or proxys), this can allow for a scientifically based tailoring of communications, now made much more easier by the new communication technologies.

More basically, research in the field of TP, like in other related to personality in relation to contexts, make appear how the behavior is in many cases the results of the interaction between the person and the situation. Present oriented people are not "bad apples", inevitably 
destined for difficulties to manage health, education, environmental issues and so on. More surely, there is "bad barrels", namely some context where the time frame is design in the wrong way, and then could be not only ineffective but eventually dissuasive. Practitioners and scientists would gain in working together to design new tools, massages and approaches, to improve the ecological validity of our nascent models in TP research, and to introduce evidence-based practice that could prevent from creating inequalities by our action.

\section{References}

Adams, J., \& Nettle, D. (2009). Time perspective, personality and smoking, body mass, and physical activity: An empirical study. British journal of health psychology, 14(1), 83105.

Agnew, C. R., \& Loving, T. J. (1998). Future time orientation and condom use attitudes, intentions, and behavior. Journal of Social Behavior and Personality, 13, 755-764.

Alvos, L., Gregson, R. A. M., \& Ross, M. W. (1993). Future time perspective in current and previous injecting drug users. Drug and Alcohol Dependence, 31(2), 193-197.

Angott, A. M. (2010). What Causes Delay Discounting? Consulté de http://deepblue.lib.umich.edu/handle/2027.42/78754

Apostolidis, T., Fieulaine, N., Simonin, L., \& Rolland, G. (2006). Cannabis use, time perspective and risk perception: Evidence of a moderating effect. Psychology and health, 21(5), 571-592.

Apostolidis, T., Fieulaine, N., \& Soulé, F. (2006). Future time perspective as predictor of cannabis use: Exploring the role of substance perception among French adolescents. Addictive Behaviors, 31, 2339-2343. doi:10.1016/j.addbeh.2006.03.008

Bachman, J. G., Johnson, L. D., \& O'malley, P. M. (1998). Explaining recent increases in students' marijuana use: impacts of perceived risks and disapproval, 1976 through 1996. American journal of public health, 88(6), 887-892.

Baker, F., Johnson, M. W., \& Bickel, W. K. (2003). Delay discounting in current and neverbefore cigarette smokers: Similarities and differences across commodity, sign, and magnitude. Journal of Abnormal Psychology, 112(3), 382.

Bandura, A. (1991). Social cognitive theory of self-regulation. Organizational behavior and human decision processes, 50(2), 248-287. 
Barber, L.K., Munz, D.C., Bagsby, P.G., \& Grawitch, M.J. (2009). When does time perspective matter? Self-control as a moderator between time perspective and academic achievement. Personality and Individual Differences, 46, 250-253.

Barnett, E., Spruijt-Metz, D., Unger, J. B., Rohrbach, L. A., Sun, P., \& Sussman, S. (2013). Bidirectional associations between future time perspective and substance use among continuation high-school students. Substance use \& misuse, 48(8), 574-580.

Baumeister, R.F., Gailliot, M., DeWall, C.N., \& Oaten, M. (2006). Self-Regulation and Personality: How Interventions Increase Regulatory Success, and How Depletion Moderates the Effects of Traits on Behavior. Journal of Personality, 74, 1773-1801.

Baumeister, R. F., Vohs, K. D., \& Tice, D. M. (2007). The strength model of self-control. Current Directions in Psychological Science, 16, 396-403.

Bickel, W. K., Odum, A. L., \& Madden, G. J. (1999). Impulsivity and cigarette smoking: delay discounting in current, never, and ex-smokers. Psychopharmacology, 146(4), 447454.

Björgvinsson, T., \& Wilde, G.J.S. (1996). Risky health and safety habits related to perceived value of the future. Safety Science, 22, 27-33.

Boney-McCoy, S.B., Gibbons, F.X., Reis, T.J., Gerrard, M., Luus, C.A. \& VonWald Suka, A. (1992) Perceptions of smoking risk as a function of smoking status. Journal of Behavioral Medicine, 15, 469-488.

Boyd, J. N., \& Zimbardo, P. G. (2005). Time perspective, health, and risk taking. In A. Strathman, \& J. Joireman, (Eds.), Understanding Behavior in the Context of Time (pp. 85-107). Mahwah, Erlbaum.

Brewer, N. T., Weinstein, N. D., Cuite, C. L., \& Herrington, J. E. (2004). Risk perceptions and their relation to risk behavior. Annals of Behavioral Medicine, 27(2), 125-130.

Brody, G. H., \& Ge, X. (2001). Linking parenting processes and self-regulation to psychological functioning and alcohol use during early adolescence. Journal of Family Psychology, 15, 82- 94 .

Burger, J. M., and H. M. Cooper (1979). The desirability of control. Motivation and Emotion, $3,381-393$.

Burger, J. M. (1992). Desire for control: Personality, social and clinical perspectives. New York, Plenum.

Chapman, G.B., \& Coups, E.J. (1999). Time preferences and preventive health behavior. Medical decision making, 19(3), 307-314.

Chapman, G.B. (2001). Time preferences for the very long term. Acta Psychologica, 108(2), 
95- 116.

Chapman, G.B., Brewer, N.T., Coups, E.J., Brownlee, S., Leventhal, H., \& Leventhal, E.A. (2001). Value for the future and preventive health behavior. Journal of experimental psychology Applied. 7(3), 235-250.

Chavarria, J., Allan, N. P., Moltisanti, A., \& Taylor, J. (2015). The effects of present hedonistic time perspective and past negative time perspective on substance use consequences. Drug and alcohol dependence, 152, 39-46.

Coffey, S. F., Gudleski, G. D., Saladin, M. E., \& Brady, K. T. (2003). Impulsivity and rapid discounting of delayed hypothetical rewards in cocaine-dependent individuals. Experimental and Clinical Psychopharmacology, 11(1), 18

Cottle T. J. (1968). The location of experience : a manifest time orientation. Acta Psychologica, 28, 129-149.

Crockett, R.A., Weinman, J., Hankins, M., \& Marteau, T. (2009). Time orientation and health- related behaviour: measurement in general population samples. Psychology \& Health, 24(3), 333-350.

Crockett, R. A., Weinman, J., Hankins, M., \& Marteau, T. (2009). Time orientation and health-related behaviour: Measurement in general population samples. Psychology and Health, 24(3), 333-350.

Daugherty, J. R., \& Brase, G. L. (2010). Taking time to be healthy: Predicting health behaviors with delay discounting and time perspective. Personality and Individual Differences, 48(2), 202-207.

Fieulaine, N., Martinez, F., \& others. (2011). About the fuels of self-regulation: Time perspective and desire for control in adolescents substance use.

Fieulaine, Nicolas, \& Martinez, F. (2010). Time under control: Time perspective and desire for control in substance use. Addictive Behaviors, 35, 799-802.

doi:10.1016/j.addbeh.2010.03.022

Finke, M. S. (2005). Time orientation and economics. In A. Strathman, \& J. Joireman (Eds.), Understanding Behavior in the Context of time (pp. 109-123). Mahwah, Lawrence Erlbaum.

Fuchs, V.R. (1982). Time preference and health: An exploratory study. In: V.R. Fuchs (Ed.), Economic aspects of health (pp.93-120). Chicago, University of Chicago Press.

Fujita, K., Trope, Y., Liberman, N., \& Levin-Sagi, M. (2006). Construal levels and selfcontrol. Journal of Personality and Social Psychology, 90(3), 351.

Gebhardt, W.A., \& Brosschot, J.F. (2002). Desirability of control: psychometric properties 
and relations with locus of control, personality, coping, mental and somatic complaints. European Journal of Personality, 16, 423-438.

Giordano, L. A., Bickel, W. K., Loewenstein, G., Jacobs, E. A., Marsch, L., \& Badger, G. J. (2002). Mild opioid deprivation increases the degree that opioid-dependent outpatients discount delayed heroin and money. Psychopharmacology, 163(2), 174-182. doi:10.1007/s00213-002-1159-2

Griva, F., Anagnostopoulos, F., \& Potamianos, G. (2013). Time perspective and perceived risk as related to mammography screening. Women \& health, 53(8), 761-776.

Guthrie, L. C., Butler, S. C., \& Ward, M. M. (2009). Time perspective and socioeconomic status: A link to socioeconomic disparities in health? Social Science \& Medicine, 68(12), 2145-2151.

Hall, P. A., \& Fong, G. T. (2007). Temporal self-regulation theory: A model for individual health behavior. Health Psychology Review, 1(1), 6-52.

Hall, P. A., Fong, G. T., Yong, H. H., Sansone, G., Borland, R., \& Siahpush, M. (2012). Do time perspective and sensation-seeking predict quitting activity among smokers? Findings from the International Tobacco Control (ITC) Four Country Survey. Addictive behaviors, 37(12), 1307-1313.

Hammersley, R.; Jenkins, R. \& Reid, M. (2001) Cannabis use and social identity. Addiction Research \& Theory, 9, 133-150.

Heil, S. H., Johnson, M. W., Higgins, S. T., \& Bickel, W. K. (2006). Delay discounting in currently using and currently abstinent cocaine-dependent outpatients and non-drug-using matched controls. Addictive Behaviors, 31(7), 1290-1294.

Henson, J.M., Carey, K.B., Carey, M.P., \& Maisto, S.A. (2006). Associations Among Health Behaviors and Time Perspective in Young Adults: Model Testing with Boot-Strapping Replication. Journal of Behavioral Medicine, 29(2), 127-137.

Jochemczyk, Ł., Pietrzak, J., Buczkowski, R., Stolarski, M., \& Markiewicz, Ł. (2016). You only live once: present-hedonistic time perspective predicts risk propensity. Personality and Individual Differences.

Johnson, M. W., Bickel, W. K., \& Baker, F. (2007). Moderate drug use and delay discounting: A comparison of heavy, light, and never smokers. Experimental and Clinical Psychopharmacology, 15(2), 187.

Joireman, J., Balliet, D., Sprott, D., Spangenberg, E., \& Schultz, J. (2008). Consideration of future consequences, ego-depletion, and self-control: Support for distinguishing between CFC- immediate and CFC-future sub-scales. Personality and Individual Differences, 48 , 
$15-21$.

Kees, J. (2010). Temporal framing in health advertising: The role of risk and future orientation. Journal of Current Issues \& Research in Advertising, 32(1), 33-46.

Keough, K. A., Zimbardo, P. G., \& Boyd, J. N. (1999). Who's smoking, drinking, and using drugs? Time perspective as a predictor of substance use. Basic and Applied Social Psychology, 21(2), 149-164.

Kilmer, J. R., Hunt, S. B., Lee, C. M., \& Neighbors, C. (2007). Marijuana use, risk perception, and consequences: Is perceived risk congruent with reality?. Addictive behaviors, 32(12), 3026-3033.

Kirby, K. N., Petry, N. M., \& Bickel, W. K. (1999). Heroin addicts have higher discount rates for delayed rewards than non-drug-using controls. Journal of Experimental Psychology: General, 128(1), 78.

Klingemann, H. (2001). The Time Game: Temporal perspectives of patients and staff in alcohol and drug treatment. Time \& Society, 10(2-3), 303-328.

Lavelle, T., Hammersley, R., \& Forsyth, A. (1991). Personality as an explanation of drug use. Journal of Drug Issues, 21(3), 593-604.

Lende, D. H., \& Smith, E. O. (2002). Evolution meets biopsychosociality: an analysis of addictive behavior. Addiction, 97(4), 447-458.

Lennings, C. J. (1991). The Schalling Sensation Seeking and Impulsivity Scales: Their relationship to time perspective and time awareness, a preliminary report. Psychological reports, 69(1), 131-136.

MacKillop, J., Mattson, R. E., MacKillop, E. J. A., Castelda, B. A., \& Donovick, P. J. (2007). Multidimensional assessment of impulsivity in undergraduate hazardous drinkers and controls. Journal of studies on alcohol and drugs, 68(6), 785-788.

Madden, G. J., Petry, N. M., Badger, G. J., \& Bickel, W. K. (1997). Impulsive and selfcontrol choices in opioid-dependent patients and non-drug-using control patients: Drug and monetary rewards. Experimental and Clinical Psychopharmacology, 5(3), 256.

Milfont, T. L., Andrade, P. R., Pessoa, V. S., \& Belo, R. P. (2008). Testing zimbardo time perspective inventory in a brazilian sample. Interamerican Journal of Psychology, 42(1), $49-58$.

Mitchell, S. H. (2003). Discounting the value of commodities according to different types of cost. Choice, behavioral economics and addiction, 339-357.

Mitchell, S. H. (2004). Effects of short-term nicotine deprivation on decision-making: delay, uncertainty and effort discounting. Nicotine \& tobacco research, 6(5), 819-828. 
Mitchell, S. H., \& Wilson, V. B. (2012). Differences in delay discounting between smokers and nonsmokers remain when both rewards are delayed. Psychopharmacology, 1-14.

Orbell, S. \& Kyriakaki, M. (2008) Temporal framing and persuasion to adopt preventive health behavior: Moderating effects of individual differences in consideration of future consequences on sunscreen use. Health Psychology, 27, 770-779,

Orbell, S., \& Hagger, M. S. (2006). Temporal framing and the decision to take part in Type 2 diabetes screening: Effects of individual differences on persuasion. Health Psychology, $25,537-548$.

Orbell, S., Perugini, M., \& Rakow, T. (2004). Individual differences in sensitivity to health communications: Consideration of future consequences. Health Psychology, 23, 388396.

Peretti-Wattel, P. (2003) Neutralization theory and the denial of risk: Some evidence from cannabis use among French adolescents. British Journal of Sociology, 54, 21-42.

Petry, N. M. (2001). Pathological gamblers, with and without substance abuse disorders, discount delayed rewards at high rates. Journal of Abnormal Psychology, 110(3), 482.

Petry, N. M., Bickel, W. K., \& Arnett, M. (1998). Shortened time horizons and insensitivity to future consequences in heroin addicts. Addiction, 93(5), 729-738.

Rasmussen, H. N., Wrosch, C., Scheier, M. F., \& Carver, C. S. (2006). Self-regulation processes and health: The importance of optimism and goal adjustment. Journal of Personality, 74, 1721-1747.

Reynolds, B. (2006). A review of delay-discounting research with humans: relations to drug use and gambling. Behavioural Pharmacology, 17(8), 651-667. doi:10.1097/FBP.0b013e3280115f99

Richard, R., van der Pligt, J., \& de Vries, N. (1996). Anticipated affect and behavioral choice. Basic and Applied Social Psychology, 18(2), 111-129.

Rosenbloom, T. (2003) Risk evaluation and risky behavior of high and low sensation seekers. Social Behavior and Personality, 31, 375-386.

Sayette, M. A., Loewenstein, G., Griffin, K. M., \& Black, J. J. (2008). Exploring the cold-tohot empathy gap in smokers. Psychological science, 19(9), 926.

Skinner, E. A. (1996). A guide to constructs of control. Journal of Personality and Social Psychology, 71, 549-570.

Smart, R. G. (1968). Future time perspectives in alcoholics and social drinkers. Journal of Abnormal Psychology; Journal of Abnormal Psychology, 73(1), 81. 
Sniehotta, F. F., Presseau, J., \& Araújo-Soares, V. (2014). Time to retire the theory of planned behaviour.

Strathman, A., Gleicher, F., Boninger, D. S., \& Edwards, C. S. (1994). The consideration of future consequences: Weighing immediate and distant outcomes of behavior. Journal of personality and social psychology, 66(4), 742.

Svenson, O., \& Karlsson, G. (1989). Decision-Making, Time Horizons, and Risk in the Very Long-Term Perspective. Risk Analysis, 9(3), 385-399.

Terry-McElrath, Y. M., O'Malley, P. M., Patrick, M. E., \& Miech, R. A. (2017). Risk is still relevant: Time-varying associations between perceived risk and marijuana use among US 12th grade students from 1991 to 2016. Addictive Behaviors.

Trope, Y., \& Liberman, N. (2003). Temporal construal. Psychological review, 110(3), 403.

Virgili, M., Owen, N., \& Severson, H. H. (1991). Adolescents' smoking behavior and risk perceptions. Journal of substance abuse, 3(3), 315-324.

Vuchinich, R. E., \& Simpson, C. A. (1998). Hyperbolic temporal discounting in social drinkers and problem drinkers. Experimental and Clinical Psychopharmacology, 6(3), 292.

Wills, T.A., Sandy, J.M., \& Yaeger, A.M. (2001). Time perspective and early-onset substance use: A model based on stress-coping theory. Psychology of Addictive Behaviors, 15, 118125 .

Wills, T.A., \& Stoolmiller, M. (2002). The role of self-control in early escalation of substance use. Journal of Consulting and Clinical Psychology, 70, 986-997.

Wills, T.A., Ainette, M.G., Stoolmiller, M., Gibbons, F.X., \& Shinar, O. (2008).Good selfcontrol as a buffering agent for adolescent substance use: an investigation in early adolescence with time-varying covariates. Psychology of Addictive Behaviors, 22(4), 459-471.

Wills, T. A., Pokhrel, P., Morehouse, E., \& Fenster, B. (2011). Behavioral and emotional regulation and adolescent substance use problems: a test of moderation effects in a dualprocess model. Psychology of Addictive Behaviors, 25(2), 279.

Wills, T. A., Walker, C., Mendoza, D., \& Ainette, M. G. (2006). Behavioral and emotional self- control: Relations to substance use. Psychology of Addictive Behaviors, 20, 265-278. Wininger, S. R., \& DeSena, T. M. (2012). Comparison of Future Time Perspective and SelfDetermination Theory for Explaining Exercise Behavior. Journal of Applied Biobehavioral Research, 17(2), 109-128. 
Yi, R., Johnson, M. W., Giordano, L. A., Landes, R. D., Badger, G. J., \& Bickel, W. K. (2010). The effects of reduced cigarette smoking on discounting future rewards: An initial evaluation. The Psychological Record, 58(2), 1.

Zaleski,, Z. (1994). Psychology of future orientation. Lublin, Scientific Society.

Zimbardo, P.G., \& Boyd, J.N. (1999). Putting time in perspective: A valid, reliable individual- differences metric. Journal of Personality and Social Psychology, 77, 12711288.

Kees, J. (2011). Advertising framing effects and consideration of future consequences. Journal of Consumer Affairs, 45(1), 7-32. 